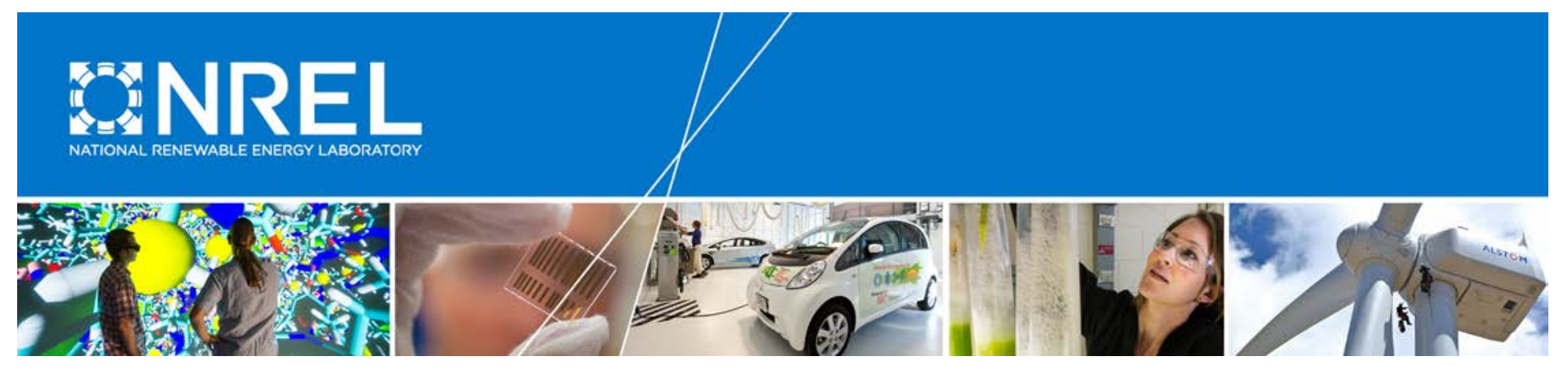

\title{
Understanding Dynamic Model Validation of a Wind Turbine Generator and a Wind Power Plant
}

\section{Preprint}

Eduard Muljadi, Ying Chen Zhang, and Vahan Gevorgian National Renewable Energy Laboratory

Dmitry Kosterev Bonneville Power Administration

To be presented at the 2016 IEEE Energy Conversion Congress and Exposition

Milwaukee, Wisconsin

September 18-22, 2016

(C) 2016 IEEE. Personal use of this material is permitted. Permission from IEEE must be obtained for all other uses, in any current or future media, including reprinting/republishing this material for advertising or promotional purposes, creating new collective works, for resale or redistribution to servers or lists, or reuse of any copyrighted component of this work in other works.

NREL is a national laboratory of the U.S. Department of Energy Office of Energy Efficiency \& Renewable Energy Operated by the Alliance for Sustainable Energy, LLC

This report is available at no cost from the National Renewable Energy Laboratory (NREL) at www.nrel.gov/publications.

Conference Paper

NREL/CP-5D00-66392

September 2016

Contract No. DE-AC36-08GO28308 


\section{NOTICE}

The submitted manuscript has been offered by an employee of the Alliance for Sustainable Energy, LLC (Alliance), a contractor of the US Government under Contract No. DE-AC36-08GO28308. Accordingly, the US Government and Alliance retain a nonexclusive royalty-free license to publish or reproduce the published form of this contribution, or allow others to do so, for US Government purposes.

This report was prepared as an account of work sponsored by an agency of the United States government. Neither the United States government nor any agency thereof, nor any of their employees, makes any warranty, express or implied, or assumes any legal liability or responsibility for the accuracy, completeness, or usefulness of any information, apparatus, product, or process disclosed, or represents that its use would not infringe privately owned rights. Reference herein to any specific commercial product, process, or service by trade name, trademark, manufacturer, or otherwise does not necessarily constitute or imply its endorsement, recommendation, or favoring by the United States government or any agency thereof. The views and opinions of authors expressed herein do not necessarily state or reflect those of the United States government or any agency thereof.

This report is available at no cost from the National Renewable Energy Laboratory (NREL) at www.nrel.gov/publications.

Available electronically at SciTech Connect http:/www.osti.gov/scitech

Available for a processing fee to U.S. Department of Energy and its contractors, in paper, from:

U.S. Department of Energy

Office of Scientific and Technical Information

P.O. Box 62

Oak Ridge, TN 37831-0062

OSTI http://www.osti.gov

Phone: 865.576.8401

Fax: 865.576.5728

Email: reports@osti.gov

Available for sale to the public, in paper, from:

U.S. Department of Commerce

National Technical Information Service

5301 Shawnee Road

Alexandria, VA 22312

NTIS http://www.ntis.gov

Phone: 800.553 .6847 or 703.605 .6000

Fax: 703.605.6900

Email: orders@ntis.gov 


\title{
Understanding Dynamic Model Validation of a Wind Turbine Generator and a Wind Power Plant
}

\author{
E. Muljadi, Fellow, IEEE, Y.C. Zhang, Senior Member, IEEE, V. Gevorgian, Member, IEEE, \\ D. Kosterev, Senior Member, IEEE
}

\begin{abstract}
Regional reliability organizations require power plants to validate the dynamic models that represent them to ensure that power systems studies are performed to the best representation of the components installed. In the process of validating a wind power plant (WPP), one must be cognizant of the parameter settings of the wind turbine generators (WTGs) and the operational settings of the WPP.

Validating the dynamic model of a WPP is required to be performed periodically. This is because the control parameters of the WTGs and the other supporting components within a WPP may be modified to comply with new grid codes or upgrades to the WTG controller with new capabilities developed by the turbine manufacturers or requested by the plant owners or operators.

The diversity within a WPP affects the way we represent it in a model. Diversity within a WPP may be found in the way the WTGs are controlled, the wind resource, the layout of the WPP (electrical diversity), and the type of WTGs used. Each group of WTGs constitutes a significant portion of the output power of the WPP, and their unique and salient behaviors should be represented individually.

The objective of this paper is to illustrate the process of dynamic model validations of WTGs and WPPs, the available data recorded that must be screened before it is used for the dynamic validations, and the assumptions made in the dynamic models of the WTG and WPP that must be understood. Without understanding the correct process, the validations may lead to the wrong representations of the WTG and WPP modeled.
\end{abstract}

Index Terms - dynamic model, electromagnetic transient, validation, wind power plant, wind turbine generator.

\section{INTRODUCTION}

$\mathrm{D}$ URING the past two decades, there has been tremendous growth in many aspects of wind power generation and related technologies. The capabilities of wind turbine generators (WTGs) have improved significantly in conjunction with the progress made in the power electronics industry, both in terms of the costs and capabilities; thus, it is now possible to build modern wind turbines that meet modern grid requirements at affordable costs.

Wind turbine installations have continued to multiply, and the penetration level of wind generation on the grid has steadily increased. Similarly, challenges in operating a power system with high penetration levels of wind power will start to appear within the next few years. In anticipation of these challenges, the wind industry and the utility industry have been moving toward developing dynamic models for WTGs and wind power plants (WPPs) in a concerted effort via the International Energy Agency and International Electrotechnical Commission. In the United States, efforts on
WTG dynamic models have been spearheaded by the Electric Reliability Council of Texas and by the Western Electricity Coordinating Council through its Renewable Energy Modeling Task Force. Similarly, at the national and regional levels, grid codes have been written to ensure that power system reliability will not be degraded by the large increase in wind power generation.

The development of a dynamic model of a WTG is the first major step toward representing it, wherein the WTG is represented correctly in the power system network instead of as a negative load. All functionalities of the WTG are modeled. The next important step is to validate the WTG dynamic model to ensure that different WTGs from different manufacturers can be represented as accurately as possible to the actual turbines.

Section II presents a discussion on WPP representation. Section III presents the dynamic model validation, followed by Section IV, which presents the dynamic simulations to validate the dynamic models. Finally, Section V gives the summary.

\section{Wind Power Plant Representation}

The dynamic model of a WPP consists of the WTG and its supporting components. It is generally acceptable to represent a large WPP as one or two turbines because simulating hundreds of turbines within a WPP is not practical, is too time consuming, and is not necessary; however, it is important to represent the dynamic behavior of the WPP as close as possible to the actual WPP because it is the collective behavior of the WPP that is important, not the behavior of an individual turbine.

\section{A. Wind Turbine Generator Representation}

Four types of WTGs are commonly used in a WPP: Type 1 induction generators, which are fixed-speed WTGs; Type 2 wound-rotor induction generators with adjustable rotor resistance, or variable-slip WTGs; Type 3 variable-speed WTGs implemented with a doubly-fed induction generator; and Type 4 variable-speed WTGs implemented with a full power converter. The first two were available in the early stages of wind power deployment, and the last two are the popular WTGs implemented during recent decades.

The dynamic model represents each type of WTG with its own capabilities and limitations. Type 1 and Type 2 require passive reactive compensation (e.g., a shunt capacitor bank). Type 3 and Type 4 can supply their own reactive power, and the reactive power can be adjusted by setting the control flags 
appropriately. Three options for reactive compensation can be chosen for operation: constant power factor, constant reactive power, and constant voltage [1]-[3].

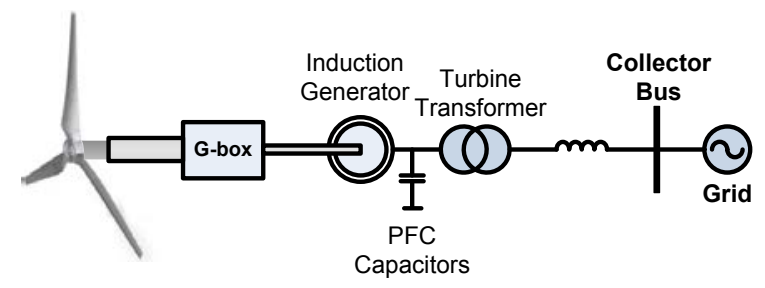

(a) Type 1 WTG

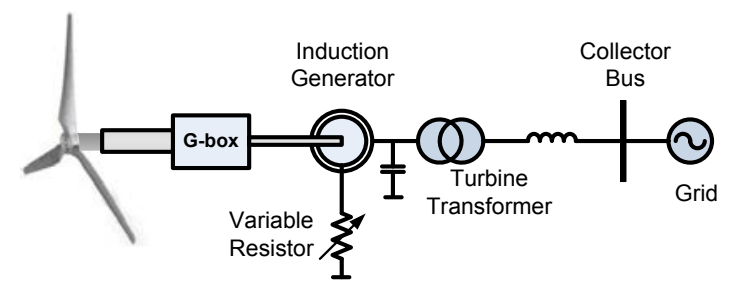

(b) Type 2 WTG

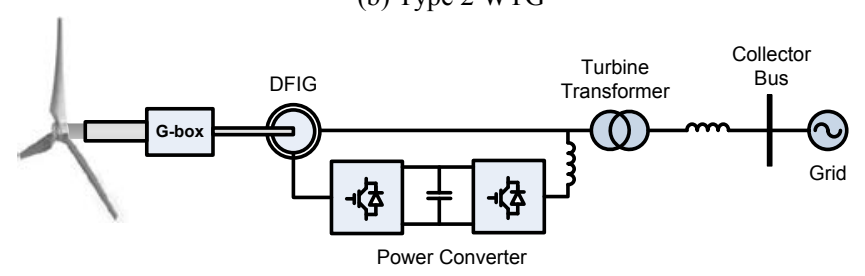

(c) Type 3 WTG

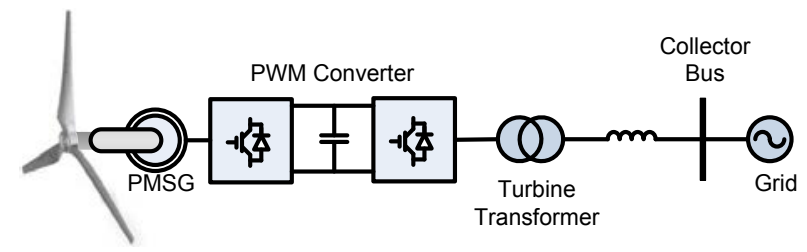

(d) Type 4 WTG

Fig. 1. Different types of WTGs

Initialization of the dynamic simulation takes place in the power flow stage of the simulation; thus, the initial values of the power generation (both real and reactive power) are set at the actual generation [1].

\section{B. Wind Power Plant Representation}

The WPP must be represented according to the actual WPP. The most common method is to represent hundreds of wind turbines as a single turbine. The method of equivalencing many turbines into a single turbine has been documented [1][-4], and it will not be repeated here.

\section{Diversity Representation}

A WPP covers a very large area; thus, there is diversity within a WPP. Diversity in a WPP can be in different forms:

- Wind resource: a group of wind turbines in one corner will experience different wind speeds due to the spatial difference or due to the landscape and the turbine locations.
- $\quad$ Types of WTGs: a WPP may consist of two groups of WTGs - one of Type 1 WTGs and another of Type 3 WTGs - and each group is about the same size in total power rating.

- Line impedance: the electrical distance between one turbine and the main substation at the point of interconnection (POI) differs among the turbines within a WPP. As such, even for the same wind condition, the voltage and phase angle at the terminals of each WTG may be slightly different from one turbine to another.

- Control setting: the control setting of one group of turbines may be different from another group of turbines-for example, to compensate for the voltage drop within the collector system. One group of turbines may be controlled to generate at unity power factor while another group is controlled to regulate the voltage at the POI.

The diversities listed above have different impacts on the WPP's response to different types of disturbances. The relay protection settings at each turbine are normally customized according to the recommended values from the manufacturer based on the regional or local grid codes and/or the request from the system operators or project developers. As a result, during a fault, each turbine will experience different voltage and current levels, and some of the turbines-usually those closest to the POI-will get disconnected from the grid while others stay connected. Thus, upon a disturbance, it can be expected that a group of turbines within a WPP may be disconnected from grid while others stay online. In a way, this makes a WPP more resilient or more forgiving to disturbance events. For example, [4] summarized an observation in a WPP in Texas for a period of one year and concluded that in a majority of faults only $14 \%$ of the events disconnect the entire WPP. And for approximately $80 \%$ of the events, only $15 \%$ of the turbines were disconnected from the grid. Thus, during the validation, we need to understand this, and we can expect that the pre-fault generation may be different from the post-fault generation. This fact needs to be reconciled during the validation process. Another option is to screen the data and validate the dynamic model using only the available data that has the same output power before and after the faults, an indication that no turbines were disconnected from the grid.

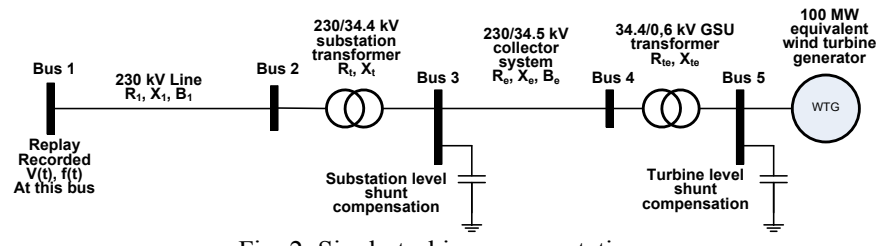

Fig. 2. Single-turbine representation

\section{Multiple-Turbine Representation}

As mentioned before, the WPP must be represented according to the actual WPP. Consideration should be given to the type of study being conducted. For planning studies, the worst-case scenarios are often considered; thus, a single-turbine 
representation of a WPP, as shown in Fig. 2, is commonly used. Other types of studies may need to use a multipleturbine representation. For example, if the interaction among groups of turbines is the main interest of study, a multipleturbine representation should be considered. For example, take a WPP which consists of $60 \%$ of Type 1 WTGs, and the rest are Type 4 WTGs operated at unity power factor (refer to Fig. 3).

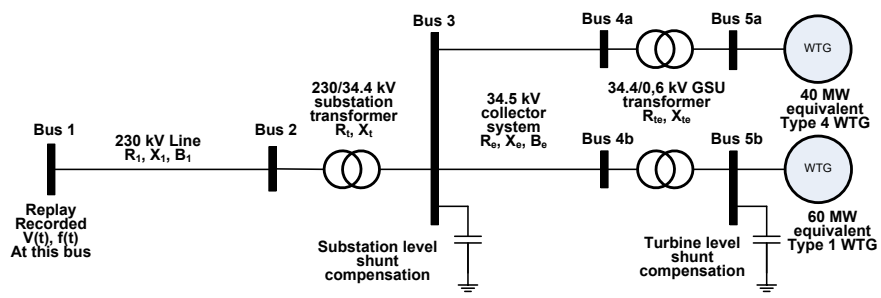

Fig. 3. Multiple-turbine representation

In this case, we need to represent the WPP using a two-turbine representation so that the significantly unique characteristics of each turbine type are included. However, , if the same WPP contains several Type 3 WTGs representing less than $2 \%$ of the total power of the WPP, these turbines do not need special representation because the impact of the Type 3 WTGs on the overall behavior of the WPP will be negligible. The small number of Type 3 WTGs can be lumped into the representation of the Type 4 WTGs because their behavior is the closest to that of the Type 3 WTGs. Thus, the representation of the WPP must be unique and include a significant proportion of the power of the total size of the WPP. Examples of multiple-turbine representations in WPP modeling have been documented in several sources [5].

\section{Dynamic Simulations to VALidate DynamiC Models}

Very often the state estimations of a power system that are captured during the short duration of a transient fault for the duration of a disturbance are not available to re-create the event for the entire system; thus, conducting a validation for an entire interconnection is not feasible or necessary, and the dynamic model validation is usually conducted for one plant at a time. The validation is normally done by using the data captured at the POI of the WPP. The voltage at the POI is then replayed to drive the simulated WPP, and the response is compared to the recorded data during the event.

\section{A. Availability of Data}

The data to validate the WPP dynamic model are not easy to get. The recent proliferation of synchrophasor units, also known as phasor measurement units (PMUs) in many parts of the power system network, makes it easier to harvest data that can be used to validate the WPP dynamic model [6]. When we obtain the data, the next step is to find the disturbance events within them. Depending on the severity of the disturbance, these events are good candidates to validate the dynamic models.

Power system planning is commonly conducted using positive-sequence-based power system software such as PSSE, PSLF, and PowerWorld. These programs are intended to solve positive-sequence cases (such as three-phase-to-ground faults). Thus, in the validations, it is preferable to use recorded data corresponding to the symmetrical faults. Also, in power system planning, dynamic model validation is designed to study the worst-case scenario; thus, often a single-turbine representation is used.

\section{B. Case 1: Wind Speed Constant}

The WPP is represented as a single turbine. The power system network is modeled up to the POI, and the control parameters are set to represent the actual settings. An example of the WPP validation is shown in Fig. 4.

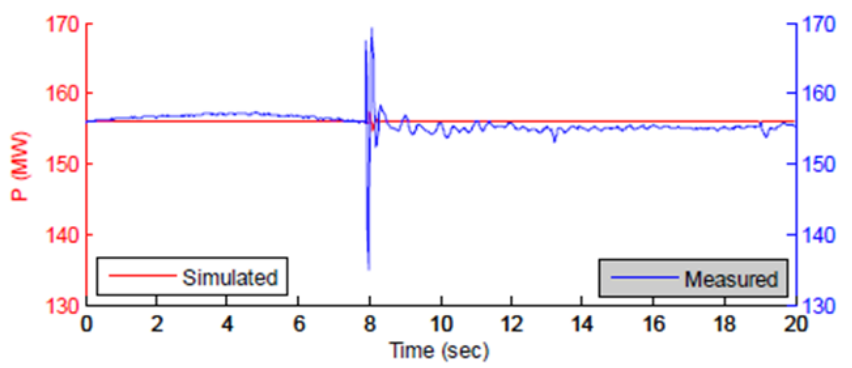

(a) Real power

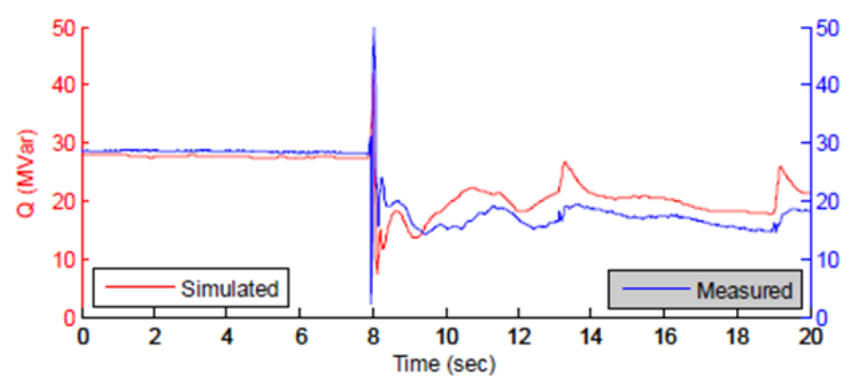

(b) Reactive power

Fig. 4. Real and reactive power comparison of the WPP validated for Case 1

Given the same voltage and the frequency at the POI, the real and reactive power from the simulation match the real and reactive power data recorded at the POI. This is a good validation example wherein the operating condition is normal, and it follows the assumptions made in the dynamic model representing the WTG. In this case, it is important that the simulation is initialized to the same operating condition at the POI where the data is recorded. Note that in Case 1, the wind speed during the disturbance was constant, as is the assumption made in the dynamic model representation.

\section{Case 2: Wind Speed Varies During the Window of Observation}

The WPP is represented as a single turbine. Case 2 is different from Case 1 in that the wind speeds vary during the recorded observation (refer to Fig. 5). The dynamic model used here does not allow modeling at varying wind speeds; thus, as shown, there is a mismatch of real power between the recorded data and the simulated output. Note that the variation of the wind speed is not large enough to affect the reactive power control. As shown here, the reactive power output of the simulation matches the recorded data very well. 


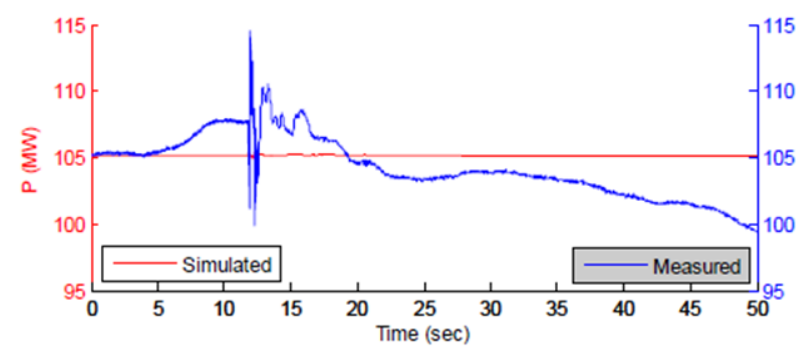

(a) Real power

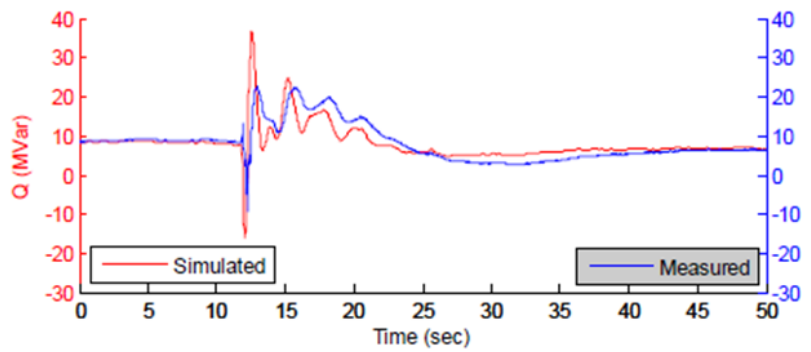

(b) Reactive power

Fig. 5. Real power mismatched and reactive power matched in the WPP validation for Case 2

\section{Case 3: Mismatch on Both the Real and Reactive Power}

In Case 3, the wind speed is shown to vary within a large power range (refer to Fig. 6). In Case 2, the small variation of real power does not significantly impact the match to the reactive power. However, as shown in Case 3, the variation of the real power output of the WPP is very large, and as such this type of recorded data is not suitable for the validation of the generic dynamic model that we used (the wind speed is assumed to be constant).

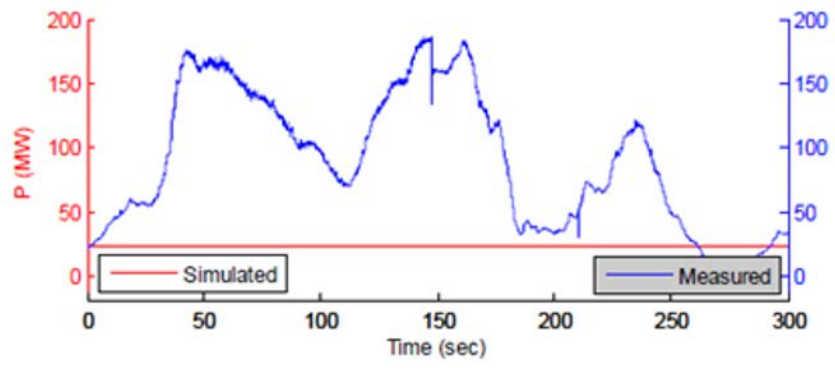

(a) Real power

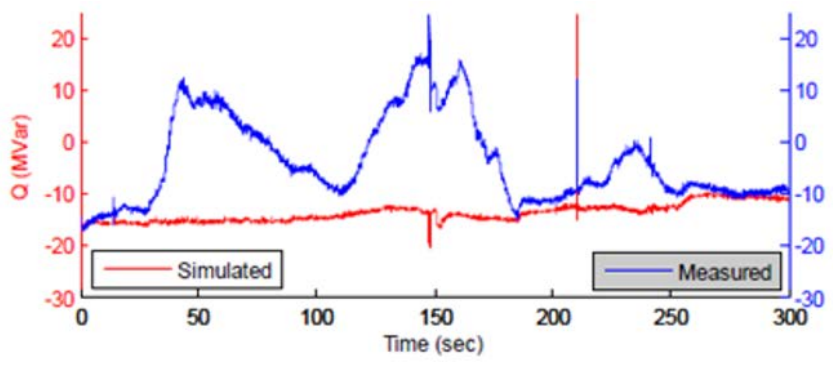

(b) Reactive power

Fig. 6. Real and reactive power mismatched in the WPP validation in for Case 3

\section{E. Case 4: Partial Drop-Off of the WTGs}

As discussed in the previous section, the diversity within a WPP makes the operating condition at individual turbines unique. Case 4 is used to illustrate the impact of diversity within a WPP. In the recorded data, it was observed that the pre-fault data of the real power output of the WPP is higher than the real power output during the post-fault condition. This is an indication that some turbines disconnected from the WPP during the transient fault. Note that in both the pre-fault and post-fault conditions, the wind speed is steady. This is evidence that the real and reactive power do not fluctuate. Thus, it is appropriate to model the WPP with two groups of WTGs: one representing the WTGs that stay connected to the grid $(91 \%$ of the total) and another group representing the WTGs that disconnected during the fault ( $9 \%$ of the total). This 9\% of the WTGs perhaps represents the WTGs closest to the POI where the impacts of the transmission faults are worse than they are in the rest of the WPP due to its diversity. Representing the WPP with a single turbine will not reflect the actual situation recorded during the fault event. Fig. 7 shows a single-line diagram of this WPP to represent the circuit configuration as the sequence of events unfolded.

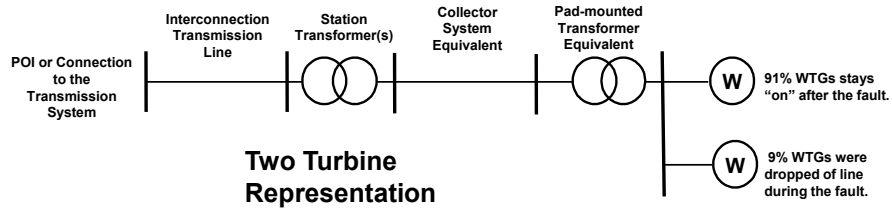

Fig. 7. Multiple-turbine representation and the recorded voltage and frequency replayed at the POI for Case 4

At the beginning of the simulation, both of the generators are connected. When the fault occurred, the voltage at the terminal of the $9 \%$ of the WTGs drops below the undervoltage relay setting that triggered the disconnection of this generator from the WPP while the rest of the generators (91\%) stay connected. Fig. 8 shows the recorded voltage and frequency (at the point of interconnection) used to drive the simulation.

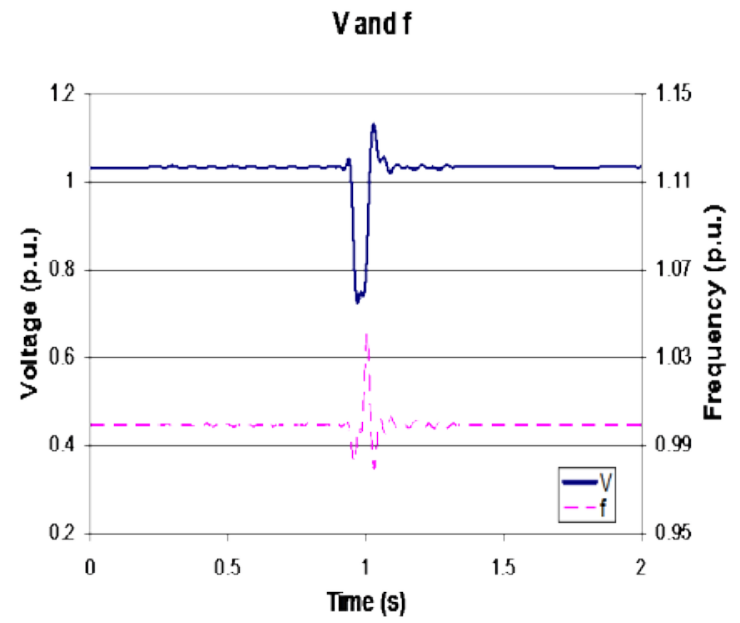

Fig. 8. Recorded voltage and frequency at the POI 
As shown in Fig. 9 (a) and Fig. 9 (b), the real and reactive power output of the WPP match the simulation results. Note that in addition to a single-turbine representation, the simulation result includes a simulation of all the WTGs within the WPP. All show a good match between the simulation and the measurement, especially during the post-fault recovery, which is the most important part of the simulation.

\section{Real Power Comparison}

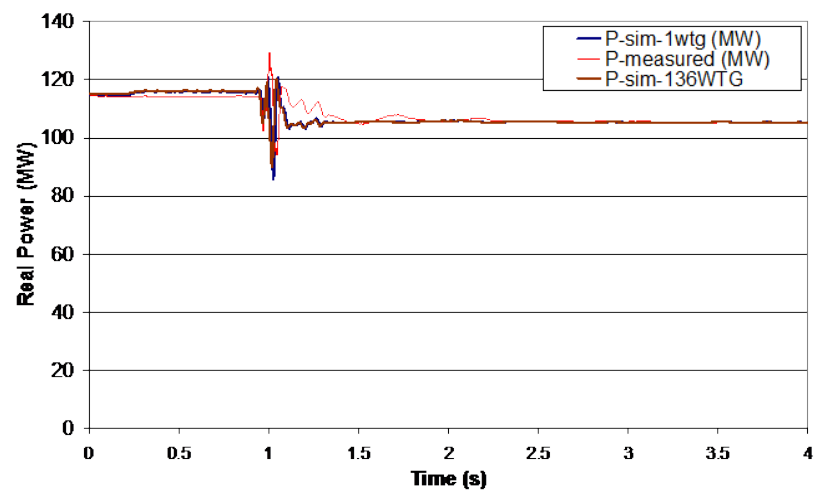

(a) Reactive power

Reactive Power Comparison

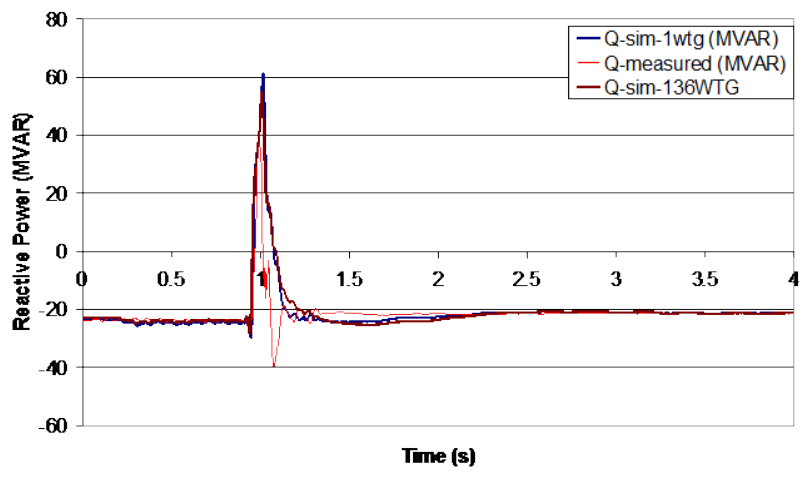

(b) Reactive power

Fig. 9. Comparison between recorded data and simulation data.

\section{CONCLUSION}

Dynamic model validations need to be done periodically to ensure that the dynamic models sent to the regional reliability organizations represent the latest setup of the WPP control parameters. In validating the dynamic model, we need to recreate the actual representation of the network connection, the sequence of events, and the correct representation of the WPP (initialization, control settings, protection settings). The data needed for the validation must be selected to represent the assumptions adopted for the dynamic model of the WTG.

For a single-turbine representation of a WPP, the ideal measurement data that should be used to validate a WPP dynamic model is from the event with a steady wind speed, the fault event is a symmetrical fault event, the reactive power controller should match the actual setting (voltage control or reactive power control), and the post fault should return the WPP to the pre-fault generation (none of the WTGs is disconnected), or all of the WTGs are disconnected. The dynamic model validation requires several data sets measured at the POI of the WPP, representing commonly occurring events in the area. During the process, the parameters of the dynamic model are tuned so that the simulated results match the actual measured data. With more data available, the accuracy of the dynamic model in representing the actual WTG or WPP will be improved.

Without understanding the process of dynamic model validation, the correct data used in validation, and the assumption made in the dynamic model, the validated model may not be representative of the actual WTG and WPP.

\section{ACKNOWLEDGMENT}

This work was supported by the U.S. Department of Energy under Contract No. DE-AC36-08-GO28308 with the National Renewable Energy Laboratory

\section{REFERENCES}

[1] Western Electricity Coordinating Council Wind Generator Modeling Group, WECC Wind Power Plant Power Flow Modeling Guide, https://www.wecc.biz/Reliability/WECC $\% 20$ Wind $\% 20 P l a n t \% 20$ Power\%20Flow\%20Modeling\%20Guide.pdf, May 2008.

[2] J. Brochu, C. Larose, and R. Gagnon, "Generic equivalent collector system parameters for large wind power plants," IEEE Trans. Energy Convers., vol. 26, no. 2, June 2011.

[3] E. Muljadi, C.P. Butterfield, A. Ellis, J. Mechenbier, J. Hochheimer, R. Young, N. Miller, R. Delmerico, R. Zavadil, and J. C. Smith, "Equivalencing the collector system of a large wind power plant," presented at the 2006 IEEE Power Engineering Society General Meeting, Montreal, Quebec, Canada, June 18-22, 2006, http://www.nrel.gov/docs/fy06osti/38940.pdf.

[4] E. Muljadi, Z. Mills, R. Foster, J. Conto, and A. Ellis, "Fault analysis at a wind power plant for one year observation," in Proc. 2008 IEEE Power Energy Soc. Gen. Meeting (PES GM), pp. 1-7.

[5] E. Muljadi, S. Pasupulati, A. Ellis, and D. Kosterov, "Method of equivalencing for a large wind power plant with multiple turbine representation," presented at the 2008 IEEE Power Engineering Society Gen. Meeting, Pittsburgh, Pennsylvania, July 20-24, 2008, http://www.nrel.gov/docs/fy08osti/42886.pdf

[6] Y. Zhang, E. Muljadi, D. Kosterev, and M. Singh, "Wind power plant model validation using synchrophasor measurements at the point of interconnection," IEEE Trans. Sustain. Energy, vol. 6, no. 3, July 2015. 